\title{
Therapeutic Plasma Exchange: Indications and Outcomes. Single-Center Registry
}

\author{
Fakhriya Alalawi, Ayman Aly Seddik, Kashif Gulzar, Marwa Tagelsir Ahmed, Dileep Kovilazhikam, \\ Lalimole Sony, Amna Alhadari
}

\section{ABSTRACT}

\begin{abstract}
Introduction: Therapeutic plasma exchange is used to manage immunemediated diseases as early as 1970th. Nevertheless, the evidence beyond the therapeutic indication is still anecdotal and depends on observational data and national registries from different parts of the world. Aim of the Study: To review the use of therapeutic plasma exchange (TPE) to manage different conditions in the Dubai Hospital-nephrology department and benchmark against standard indications categories by American Society of Apheresis (ASFA) guidelines.
\end{abstract}

Methods: The study included all adult patients who performed TPE in Dubai Hospital during 24 months period from January 2017 until December 2019. Patient demographics, indications, anticoagulation used, the number of sessions, duration of hospitalization, ICU admission, mortality outcome, and occurrence of procedure-related complications were included.

Results: During the 24 months, 142 TPE sessions were performed for 33 registered patients (an average of 4.3 sessions/patient). The most common indications for TPE use in our registry were nephrology-related indications in 119 sessions $(85 \%)$, while non-nephrology indications contributed for 21 sessions (15\%). Among Nephrology related Indications, Thrombotic Thrombocytopenic purpura was the most common indication $(47.8 \%)$, followed by post kidney transplantation $(21 \%)$, while nonNephrology-related indications were mainly for pancreatitis with Hypertriglyceridemia (9.2\%). Complications arose in 2 sessions $(1.4 \%)$, and mortality occurred in one $(3 \%)$ critically ill patient related to nonprocedure consequences and the severity of the underlying disease.

Conclusion: Our registry data confirm the safety of therapeutic plasma exchange in a professional, well-equipped nephrology setting when used for proper evidence-based indications with a lower rate of morbidity and mortality.

Keywords: Albumin, anticoagulation, fresh frozen plasma (FFP), therapeutic plasma exchange (TPE), thrombotic thrombocytopenic purpura (TTP).

\section{INTRODUCTION}

Plasmapheresis is a general word for any kind of apheresis, which removes plasma, while therapeutic Plasma exchange (TPE) involves the replacement of the removed plasma making large volume procedures possible. The typical goal is to exchange 1 to 1.5 times the estimated plasma volume per treatment [1], [2]. Therapeutic plasma exchange (TPE) has been used to manage immune-mediated diseases as early as 1970th, such as good pasture syndrome in 1975, systemic lupus erythematosus in 1976, and Thrombotic thrombocytopenic purpura in 1977 [3]-[7].

In use for over 50 years, the rationale for TPE remains based mainly on case series and retrospective studies [8]-[11]. In 1985, the American Medical Association (AMA) Council on Scientific Affairs reviewed all indications of therapeutic
Published Online: February 1, 2022

ISSN: $2736-5476$

DOI: 10.24018 /ejclinicmed.2022.3.1.163

F. Alalawi *

Department of Nephrology, Dubai Hospital, Dubai Health Authority, Dubai, United Arab Emirates.

(e-mail: fjalalawi08@yahoo.co.uk)

A. A. Seddik

Department of Nephrology, Faculty of Medicine, Ain Shams University, Cairo, Egypt.

K. Gulzar

Department of Nephrology, Dubai Hospital, Dubai Health Authority, Dubai, United Arab Emirates.

M. T. Ahmed

Department of Nephrology, Dubai Hospital, Dubai Health Authority, Dubai, United Arab Emirates.

D. Kovilazhikam

Department of Nephrology, Dubai Hospital, Dubai Health Authority, Dubai, United Arab Emirates.

L. Sony

Department of Nephrology, Dubai Hospital, Dubai Health Authority, Dubai, United Arab Emirates.

A. Alhadari

Department of Nephrology, Dubai Hospital, Dubai Health Authority, Dubai, United Arab Emirates.

*Corresponding Author

plasma exchange and categorized them into one of four categories based on the available evidence at that time:

I. Standard therapy, acceptable but not mandatory

II. Available evidence tends to favor efficacy: conventional therapy is usually tried first

III. Inadequately tested at this time

IV. No demonstrated value in controlled trials [12].

Lately, results from different randomized controlled trials, meta-analyses, and prospective studies have proven the efficacy of plasmapheresis in various renal and non-renal diseases. Among renal indications that have cumulative evidence is the Anti-glomerular basement membrane (AntiGBM) disease, anti-neutrophil cytoplasmic antibody (ANCA) associated vasculitis, recurrent focal segmental glomerulosclerosis (FSGS) post kidney transplantation, and acute allograft rejection post kidney transplantation, and it 
has provided insights into more rational use of this therapy [13]-[17]. In addition, the American Society of Apheresis recently published guidelines on the use of therapeutic plasma exchange in different disease conditions categorized to either standard therapy or adjunctive therapy or no rationale of service, depending on the strength of evidence accumulated in the past decade [18]. Nevertheless, in the new era of the COVID-19 pandemic, TPE gained a further reputation in managing severe resistant COVID cases by removing toxic cytokines, viral particles and restoring coagulation status, with favorable outcomes [19]-[21]. However, our study was done in the pre-COVID era; hence these cases were not included.

\section{AIM OF THE STUDY}

We conducted this analysis to review the indications of the therapeutic plasma exchange (TPE) to manage different conditions at the nephrology department of Dubai Hospital and associated morbidity and mortality.

\section{METHODS}

This is a retrospective observational analysis done at the nephrology department of Dubai Hospital, one of the major tertiary hospitals of Dubai health authority, in the United Arab Emirates. The study included all patients above 14 years of age, who performed TPE in Dubai Hospital for 24 months period from January 2017 until December 2019, including demographics, indications, anticoagulation used, number of sessions, duration of hospitalization, ICU admissions, mortality outcome, and occurrence of procedure-related complications.

All data tabulated and indications categorized in accordance with American Society of Apheresis categories ASFA (2) and analyzed in SPSS 24 statistical software. Data presented as Mean $\pm \mathrm{SD}$ or Median (range), number (percentage) according to data type and appropriateness.

\section{RESUlTS}

During the 24 months from January 2017 until December 2019,33 patients underwent 142 sessions of plasma exchange with an average of 4.3 sessions /patient (1-18 sessions). The patients were predominantly male $(18,54 \%)$, with a median age of $37.15(15-94) .36 .5 \%(n=12)$ were younger than 30 years old, while $45.5 \%(n=15)$ and $18.2 \%(n=6)$ were between 30-50 years, and older than 50 years respectively.

\section{A. Indications and Number of Sessions}

Table I and Fig. 1 show the indications of therapeutic plasma exchange categorized as per the American Society of Apheresis categories and the underlying grades of evidence. The most common indications for TPE use in our registry were the nephrology-related indications in 21 patients, who underwent 119 sessions (85\%), while the non-nephrology indications contributed to the rest (12 patients, 21 sessions, $15 \%)$.

Thrombotic Thrombocytopenic purpura was the most common indication. 13 patients (39\%) underwent $67(47.8 \%)$ sessions, followed by kidney transplantation related complications $\{\mathrm{n}=3,9 \%$, had 30 sessions $(21 \%)\}$, Systemic Lupus erythematosus (SLE) with rapidly progressive lupus for 3 patients ( $9 \%$ of the total population, had $12 \%$ sessions) and myeloma kidney in multiple myeloma. Non-Nephrologyrelated indications for TPE in our data included mainly pancreatitis secondary to Hypertriglyceridemia $(30 \%, \mathrm{n}=10)$, underwent 13 (9.2\%) sessions, and toxic epidermal necrolysis and Gillian-Barre syndrome with 5 sessions each (3.57\%). Table I shows the cases categories as per AFSA-categories and the underlying level of evidence for the use of therapeutic plasma exchange as part of therapeutic management. Table II shows the number of cases treated with TPE, the average number of sessions, duration of hospitalization, and age distribution. Fig. 1 shows general indications of TPE in our center during the study period.

TABLE I: TPE INDICATIONS, AGE, NUMBER OF SESSIONS AND HOSPITALIZATIONS

\begin{tabular}{|c|c|c|c|c|}
\hline ASFA Category and Level of Evidence & Indication (Number of cases) (\%) & $\begin{array}{c}\text { Age } \\
\text { Median (Range) }\end{array}$ & $\begin{array}{l}\text { No. of Sessions Median } \\
\text { (range) }\end{array}$ & $\begin{array}{l}\text { Hospital Duration } \\
\text { Median (range) }\end{array}$ \\
\hline \multirow{5}{*}{ Category I - 1A - Renal Indication } & TTP/HUS $2(6 \%)$ & $32(6)$ & $5(2)$ & $6.5(50$ \\
\hline & TTP $8(24.2 \%)$ & $31.5(32)$ & $4(17)$ & $8(22)$ \\
\hline & TTP /acquired $1(3 \%)$ & 33 & 3 & 5 \\
\hline & TTP/ Myelodysplatic Syndrome $1(3 \%)$ & 94 & 5 & 20 \\
\hline & TTP/REFRACTORY $1(3 \%)$ & 50 & 4 & 5 \\
\hline Category I - 1B - Neurology Indication & $\begin{array}{c}\text { GUIANNE BARRE SYNDROME - } \\
\text { (Acute Motor Sensory Polyneuropathy) } \\
1(3 \%)\end{array}$ & 9 & 5 & 9 \\
\hline Category I - 1B - Renal Indication & $\begin{array}{c}\text { Anti-GBM disease with crescentic GN } \\
1(3 \%)\end{array}$ & 27 & 4 & 25 \\
\hline Category I - 1B - Renal Indication & $\begin{array}{c}\text { Post Kidney Transplant Recurrent } \\
\text { FSGS } 1(3 \%)\end{array}$ & 24 & 14 & 52 \\
\hline Category II- 2B - Renal Indication & Post kidney allograft rejection $1(3 \%)$ & 25 & 14 & 52 \\
\hline Category IIB - Renal Indication & Myeloma kidney 1(3\%) & 52 & 1 & 26 \\
\hline Category IIC - Renal Indication & SLE $3(9 \%)$ & 35 (19) & $5(2)$ & $47(40)$ \\
\hline \multirow{2}{*}{$\begin{array}{l}\text { Category III - 1C - } \\
\text { Hypertriglyceridemia With Pancreatitis }\end{array}$} & $\begin{array}{c}\text { Acute Pancreatitis/Hypertriglyceridemia } \\
\qquad 7(27 \%)\end{array}$ & $38(21)$ & 1 & 6 \\
\hline & $\begin{array}{c}\text { Recurrent } \\
\text { Pancreatitis/Hypertriglyceridemia } \\
1(3 \%)\end{array}$ & $41(14)$ & 1 & $7(7)$ \\
\hline Category III - 2C - Renal Indication & FSGS $1(3 \%)$ & 28 & 2 & 3 \\
\hline Category III - 2B & Toxic Epidermal Necrolyis $1(3 \%)$ & 15 & 5 & 4 \\
\hline
\end{tabular}




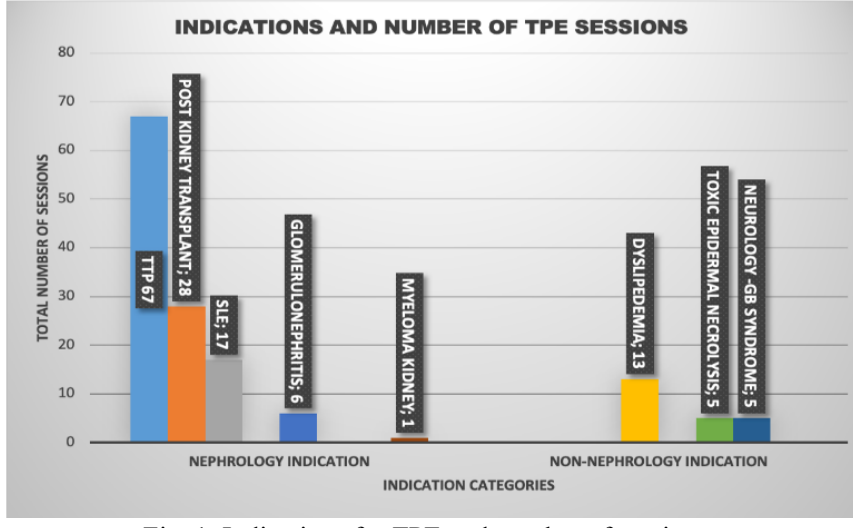

Fig. 1. Indications for TPE and number of sessions.

TABLE II: PATIENT'S DEMOGRAPHICS AND TPE SESSIONS

\begin{tabular}{lc}
\hline \multicolumn{1}{c}{ Patient Characteristics } & $\mathrm{n}=33$ \\
\hline \hline Age in Years (Median) & $37.15(15-94)$ \\
sex & \\
Male & $18(54.54 \%)$ \\
Comorbid & \\
Hypertension & $6(18.18 \%)$ \\
Diabetes Mellitus & $10(30.30 \%)$ \\
Dyslipidemia & $8(24.24 \%)$ \\
SLE & $3(9 \%)$ \\
Breast Ca & $1(3.03 \%)$ \\
Polymyalgia rheumatica & $1(3.03 \%)$ \\
Indication of Plasmapheresis & \\
Thrombotic Microangiopathy & $13(39.39 \%)$ \\
Hypertriglyceridemia & $10(30.30 \%)$ \\
Post-transplant FSGS & $2(6.06 \%)$ \\
Acute Rejection & $1(3.03 \%)$ \\
SLE & $3(9.09 \%)$ \\
Multiple Myeloma & $1(3.03 \%)$ \\
Toxic Epidermonecrolysis & $1(3.03 \%)$ \\
GBS & $1(3.03 \%)$ \\
Anti GBM & $1(3.03 \%)$ \\
No of sessions/ admission & $2.90(1-8)$ \\
Replacement fluid & \\
Albumin & $15(48.4 \%)$ \\
FFP & $16(51.6 \%)$ \\
Hospital stays in days (Median) & $14.96(1-60)$ \\
\hline
\end{tabular}

\section{B. Replacement Fluids}

Albumin alone was used in 15 cases (48.4\%), while Albumin combined with fresh frozen plasma was used in 2 patients, and fresh frozen plasma alone was used as a replacement in 16 cases $(51.6 \%)$. Table III compares both groups using either Albumin alone or FFP alone.

\section{Vascular Access and Anticoagulation used}

Vascular access used was predominantly the temporary femoral catheter in 19 cases (58\%), internal jugular catheter in 13 cases (39\%), while AVF was used in one case only $(3 \%)$. The anticoagulation used was predominantly the unfractionated heparin in 18 cases (55\%), low molecular weight heparin in 6 cases $(18 \%)$, and regional citrate anticoagulation in 2 patients (6\%), while no anticoagulation was used in 7 patients (21\%).

\section{Other Therapies used in Conjunction with TPE}

Other therapies used in conjunction with the therapeutic plasma exchange in our registry included pulse steroids (in 3 cases, 9\%) with thrombotic thrombocytopenic purpura (TTP) and transplant patients with recurrent FSGS. In addition, IVIG was used in 1 case with post kidney transplant antibodymediated rejection, Rituximab (anti-CD 20 antibodies) in 2 cases $(6 \%)$ with TTP, bortezomib in 1 case $(3 \%)$ with refractory TTP and Mycophenolate mofetil in two cases (6\%) with TTP.

\section{E. Complications during the Procedure}

Complications occurred in 2 sessions out of 142 sessions (1.4\%); allergic reaction to IVIG given after the session of TPE in post kidney transplant patient with acute allograft rejection and lastly volume overload, resulted from replacement fluid in a patient with acute pancreatitis and Hypertriglyceridemia.

TABLE III: COMPARASION OF BOTH GROUPS USING EITHER ALBUMIN OR FFP

\begin{tabular}{|c|c|c|c|}
\hline & Albumin $(n=15,48.39 \%)$ & $\mathrm{FFP}(\mathrm{n}=16,51.61 \%)$ & p-value \\
\hline Age in Years (Median) & $34.2(15-50)$ & $40.5(24-94)$ & 0.228791 \\
\hline \multicolumn{4}{|l|}{ Sex } \\
\hline Male & Male $=10(66.66 \%)$ & $7(43.75 \%)$ & 0.200089752 \\
\hline \multicolumn{4}{|l|}{ Comorbid } \\
\hline Hypertension & $6(40 \%)$ & $3(18.75 \%)$ & 0.192709582 \\
\hline Diabetes Mellitus & $8(53.33 \%)$ & $4(25 \%)$ & 0.105551668 \\
\hline Dyslipidemia & $6(40 \%)$ & $1(6.25 \%)$ & 0.024705382 \\
\hline \multicolumn{4}{|l|}{ Indication of Plasmapheresis } \\
\hline Hypertriglyceridemia & $9(60 \%)$ & $1(6.25 \%)$ & 0.001377606 \\
\hline Thrombotic Microangiopathy & 0 & $13(81.25)$ & $<0.005$ \\
\hline Post-transplant FSGS & $2(13.33 \%)$ & 0 & 0.157299 \\
\hline Acute Rejection & $1(6.66 \%)$ & 0 & 0.293778936 \\
\hline SLE & $2(13.33 \%)$ & $1(6.25 \%)$ & 0.505008845 \\
\hline Multiple Myeloma & 0 & $1(6.25 \%)$ & 0.293778936 \\
\hline Toxic Epidermonecrolysis & $1(6.66 \%)$ & 0 & 0.293778936 \\
\hline No: of sessions/ admission & $3.8(1-14)$ & $4.75(1-18)$ & 0.609389 \\
\hline Hospital stay in days (Median) & $20.07(4-60)$ & $10.5(1-26)$ & 0.138865 \\
\hline \multicolumn{4}{|l|}{ Complications } \\
\hline Allergic reactions & $1(6.66 \%)$ & 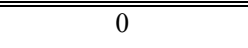 & 0.317311 \\
\hline Fluid overload & $1(6.66 \%)$ & 0 & 0.317311 \\
\hline
\end{tabular}


TABLE IV: MORBIDITY AND MORTALITY IN PATIENTS WHO UNDERWENT TPE

\begin{tabular}{|c|c|c|c|}
\hline \multicolumn{4}{|c|}{ ICU Admissions and Mortality Reported } \\
\hline INDICATION CATEGORY BY ASFA & & ICU admissions & Mortality \\
\hline \multirow{5}{*}{$\begin{array}{l}\text { CATEGORY I - 1A - RENAL } \\
\text { INDICATION }\end{array}$} & TTP- HEMOLYTIC UREMIC SYNDROME & 0 & 0 \\
\hline & TTP & $2(6 \%)$ & $1(3 \%)$ \\
\hline & TTP-ACQUIRED & 0 & 0 \\
\hline & TTP-MYELODYSPLASTIC SYNDROME & 0 & 0 \\
\hline & TTP-REFRACTORY & 0 & 0 \\
\hline $\begin{array}{l}\text { CATEGORY I - 1B - NEUROLOGY } \\
\text { INDICATION }\end{array}$ & NEUROLOGY- GUILLAIN BARRE SYNDROME & $1(3 \%)$ & 0 \\
\hline $\begin{array}{l}\text { CATEGORY I - 1B - RENAL } \\
\text { INDICATION }\end{array}$ & GLOMERULONEPHRITIS-Anti-GBM disease & 0 & 0 \\
\hline CATEGORY I -1B - RENAL INDICATION & KIDNEY TRANSPLANT-with RECURRENT FSGS & 0 & 0 \\
\hline $\begin{array}{l}\text { CATEGORY II- 2B - RENAL } \\
\text { INDICATION }\end{array}$ & KIDNEY TRANSPLANT-ACUTE ALLOGRAFT REJECTION & 0 & 0 \\
\hline CATEGORY IIB- RENAL INDICATION & MULTIPLE MYELOMA-MYELOMA KIDNEY & 0 & 0 \\
\hline CATEGORY IIC - RENAL INDICATION & SLE & $2(6 \%)$ & 0 \\
\hline CATEGORY III - 1C - & ACUTE PANCREATITIS- HYPERTRIGLYCERIDEMIA & $1(3 \%)$ & 0 \\
\hline $\begin{array}{l}\text { CATEGORY III - 2C- RENAL } \\
\text { INDICATION }\end{array}$ & GLOMERULONEPHRITIS -FSGS & 0 & 0 \\
\hline CATEGORY III - 2B & DERMATOLOGY-TOXIC EPIDERMAL NECROLYSIS & $1(3 \%)$ & 0 \\
\hline
\end{tabular}

\section{F. Mortality}

TPE was done either in the nephrology ward (25 patients $(75.8 \%))$ or the intensive care unit (ICU) (8 patients, $24.2 \%)$ sittings, according to the patient condition before the procedure; however, it was performed in ICU setting not as procedure-related but as disease severity related. In our registry, mortality occurred in a single case (3\%) with severe TTP related to critical illness (Table IV).

\section{DISCUSSION}

Therapeutic plasmapheresis is a process to remove pathological toxins from the body. With available upgraded machines, targeted selective pathological components can be removed, which results in a tremendous improvement in various disorders [22]. TPE is considered safe if performed by trained nurses [23], [24] and associated with occasional mild side effects. Though TPE is a high-risk procedure done in the ICU setting in most centers, in our center, TPE is performed in the general ward with expert hands, handling any expected complication carefully. In our study group, only two patients $(1.4 \%)$ had an adverse impact during TPE, while [24] reported that 3\% of TPE patients had adverse effects. The main indications of therapeutic plasma exchange in our study patients were Thrombotic microangiopathy, allograft dysfunction, systemic lupus erythematosus, and acute pancreatitis.

\section{A. Thrombotic Microangiopathy (TMA)}

In our study, 39.39\% $(\mathrm{n}=13)$ patients were suffering from TMA and received 67 sessions (47.8\%) of plasma exchange in total, and replacement fluid was fresh frozen plasma in almost all cases. Their median hospital stay was 8.84 (1-23) days. These patients also received rituximab $(\mathrm{n}=2)$, methylprednisolone $(n=2)$, bortezomib $(n=1)$, mycophenolate mofetil $(n=2)$ and cyclosporine $(n=1) .6(46.15 \%)$ patients improved clinically, and their median platelet count increased by 184 (58-364). The overall survival rate was $92.31 \%$. There have been many studies appreciating the role of plasmapheresis in TMA. Reference [25] observed lower mortality rates $(\mathrm{HR}=0.034$ and $\mathrm{p}=0.001)$ regardless of disease severity in patients with infection-associated TMA treated with plasma exchange. Reference [26] reported lower organ failure scores from day 3 to 9 and improved outcomes in secondary TMA patients treated with plasma exchange. Though studies have proved the positive effect of plasma exchange on secondary TMA, the strength of data is quite limited. Still, there is growing interest in changing the plasma milieu in cases of systemic inflammation, especially sepsisinduced multi-organ failure.

\section{B. Hypertriglyceridemia complicated by Acute Pancreatitis}

$30.30 \%(n=10)$ of patients received 13 sessions of TPE as they suffered from acute pancreatitis secondary to Hypertriglyceridemia. Their replacement fluid was Albumin, and their median hospital stay was 7.3 (2-14) days. Their median pre-TPE triglyceride levels were 3401 (989-4425), which improved to 475.6 (250-1494). All patients recovered fully, and none of them had complications related to plasma exchange. For hypertriglyceridemia-induced acute pancreatitis, the standard treatment is heparin, insulin, and plasmapheresis; however, studies advocate that those patients should be treated conservatively initially. Plasma exchange is an effective method to decrease triglycerides (Up to 70\% with a single session) [27]-[30].

\section{Systemic lupus erythematosus (SLE)}

Indications in SLE where plasma exchange might be beneficial are acute life-threatening manifestations and severe therapy-resistant manifestations, like refractory SLE renal disease, diffuse alveolar hemorrhage, neuropsychiatric SLE, thrombotic thrombocytopenic purpura, catastrophic antiphospholipid syndrome, hyperviscosity syndrome, and cryoglobulinemia. In our cohort, three SLE patients required 17 sessions of TPE. Indications were severe lupus nephritis with multi organs involvement $(n=1)$, SLE with TTP $(n=1)$, and lupus carditis $(\mathrm{n}=1)$; their hospital stay was longer because of the higher morbidity of the disease. There were no TPE-related complications observed. David Aguirre et al. observed that $62.12 \%$ of SLE patients improved after plasma exchange and found it safe and effective [31], while 
Reference [32] treated 31 autoimmune disorder patients with plasma exchange, corticosteroids, immunosuppressive; however, the mortality was 35\% despite TPE.

\section{Renal allograft Rejection and FSGS}

Plasma exchange removes the preformed antibodies, so it is part of the standard treatment protocol for the treatment of Antibody-mediated rejection [33]. The most recent data depict that Antibody-mediated rejection (AMR) can be reversed safely and effectively with intensive therapy with TPE, IVIG, and adjustment of basal immunosuppression [34]-[36]. Furthermore, studies suggest that there are plasmaborne factors that increase glomerular permeability and cause focal segmental glomerulosclerosis (FSGS) [37], hence becoming a logical part of the treatment strategy of recurrent FSGS in renal allograft [38]. Reference [39] in a systemic literature review, reported a $71 \%$ remission rate (partial and complete) in post-transplant recurrent FSGS patients treated with plasma exchange. $9.09 \%(\mathrm{~N}=3)$ patients in our study group received 30 sessions for renal transplant-related indications (Post-transplant FSGS=2, $\mathrm{AMR}=1$ ). There were no treatment complications.

\section{E. Replacement Solutions for Plasma Exchange}

In plasma exchange, plasma is exchanged with a colloid replacement solution. Albumin is the preferred replacement solution mostly; allergic and febrile reactions are unlikely as it is pasteurized to inactivated viruses and easy to administer and store; still, Albumin solution may lead to a mild transient deficiency of serum proteins. Another suitable option is Plasma (Single donor), it must be type-specific, so prior blood group knowledge is needed; also, plasma is usually thawed before use. It replaces all plasma constituents, so it is generally preferred over Albumin in thrombotic thrombocytopenic purpura and existing coagulopathy [40]. In our study group, Albumin and Thawed fresh frozen plasma was used in $48.4 \% \%$ and $51.6 \%$, respectively. Allergic reactions and fluid overload side effects were associated with albumin treatments. Also, hospital stay was more (20 vs. $10.5, p=0.138)$. The overall difference between the two replacement solutions was not statistically significant. However, Shemin and colleagues found that the complication rate was higher with FFP as compared to albumin solution [41].

\section{CONCLUSION}

Our registry data confirm the safety of therapeutic plasma exchange in a professional, well-equipped nephrology setting when used for proper evidence-based indications with a lower rate of overall complications (1.4\%) and mortality rate of $3 \%$, which was mainly related to non-procedure consequences and associated with the severity of the underlying disease. Our limitations were a small number of procedures in different indications. Further registries, large-scale data, and controlled randomized trials are needed to provide substantial evidence for the impact of therapeutic plasma exchange on the outcome of different disease conditions.

\section{FUNDING}

The authors have no relevant financial support.

\section{CONFLICT OF INTEREST}

Authors declare that they do not have any conflict of interest.

\section{ETHICAL APPROVAL}

The study was approved by the scientific research committee of the Dubai Health Authority.

\section{REFERENCES}

[1] Kaplan AA, Halley SE. Plasma exchange with a rotating filter. Kidney International. 1990; 38(1): 160-6.

[2] Kaplan AA. Therapeutic plasma exchange: a technical and operational review. Journal of Clinical Apheresis. 2013; 28(1): 3-10.

[3] Okafor C, Ward DM, Mokrzycki MH, Weinstein R, Clark P, Balogun RA. Introduction and overview of therapeutic apheresis. Journal of Clinical Apheresis. 2010; 25(5): 240-9.

[4] Johnson JP, Moore Jr J, Austin HA, Balow TT. Antonovych, and CB Wilson. Therapy of anti-glomerular basement membrane antibody disease: analysis of prognostic significance of clinical, pathologic and treatment factors. Medicine. 1985; 64: 219-27.

[5] Lewis EJ, Hunsicker LG, Lan SP, Rohde RD, Lachin JM. A controlled trial of plasmapheresis therapy in severe lupus nephritis. New England Journal of Medicine. 1992; 326(21): 1373-9.

[6] McLeod BC, Wu KK, Knospe WH. Plasmapheresis in thrombotic thrombocytopenic purpura. Archives of Internal Medicine. 1980; 140(8): 1059-60.

[7] Rock GA, Shumak KH, Buskard NA, Blanchette VS, Kelton JG, Nair $\mathrm{RC}$, et al. Comparison of plasma exchange with plasma infusion in the treatment of thrombotic thrombocytopenic purpura. New England Journal of Medicine. 1991; 325(6): 393-7.

[8] Hutchison CA, Cockwell P, Reid S, Chandler K, Mead GP, Harrison J, Efficient removal of immunoglobulin free light chains by hemodialysis for multiple myeloma: in vitro and in vivo studies. Journal of the American Society of Nephrology. 2007; 18(3): 886-95.

[9] Madore F, Lazarus JM, Brady HR. Therapeutic plasma exchange in renal diseases. Journal of the American Society of Nephrology. 1996; 7(3): 367-86.

[10] Matalon A, Markowitz GS, Joseph RE, Cohen DJ, Saal SD, Kaplan B, et al. Plasmapheresis treatment of recurrent FSGS in adult renal transplant recipients. Clinical Nephrology. 2001; 56(4): 271-8.

[11] Mokrzycki MH, Kaplan AA. Therapeutic plasma exchange: complications and management. American Journal of Kidney Diseases. 1994; 23(6): 817-27.

[12] American Medical Association Panel. Current status of therapeutic plasmapheresis and related techniques: report of the AMA panel on therapeutic plasmapheresis. JAMA. 1985; 253: 819-25.

[13] Schmidt JJ, Asper F, Einecke G, Eden G, Hafer C, Kielstein JT. Therapeutic plasma exchange in a tertiary care center: 185 patients undergoing 912 treatments-a one-year retrospective analysis. BMC Nephrology. 2018; 19(1): 1-7.

[14] Walters G. Role of therapeutic plasmapheresis in ANCA-associated vasculitis. Pediatric Nephrology. 2016; 31(2): 217-25.

[15] Korkmaz S, Keklik M, Sivgin S, Yildirim R, Tombak A, Kaya ME, Therapeutic plasma exchange in patients with thrombotic thrombocytopenic purpura: a retrospective multicenter study. Transfus Apher Sci. 2013; 48(3): 353-8.

[16] Prendecki M, Pusey C. Plasma exchange in anti-glomerular basement membrane disease. La Presse Médicale. 2019; 48(11): 328-37.

[17] Xie P, Tao M, Peng K, Zhao H, Zhang K, Sheng Y, et al. Plasmapheresis therapy in kidney transplant rejection. Blood Purification. 2019; 47(1-3): 73-84.

[18] Padmanabhan A, Connelly-Smith L, Aqui N, Balogun RA, Klingel R, Meyer E, et al. Guidelines on the use of therapeutic apheresis in clinical practice-evidence-based approach from the Writing Committee of the American Society for Apheresis: the eighth special issue. Journal of Clinical Apheresis. 2019; 34(3): 171-354. 
[19] Truong AD, Auld SC, Barker NA, Friend S, Wynn AT, Cobb J, et al. Therapeutic plasma exchange for COVID-19-associated hyperviscosity. Transfusion. 2021; 61(4): 1029-1034.

[20] Gucyetmez B, Atalan HK, Sertdemir I, Cakir U, Telci L. Therapeutic plasma exchange in patients with COVID-19 pneumonia in intensive care unit: a retrospective study. Critical Care. 2020; 24: 1-4.

[21] Patidar GK, Land KJ, Vrielink H, Rahimi-Levene N, Dann EJ, AlHumaidan $\mathrm{H}$, et al. Understanding the role of therapeutic plasma exchange in COVID-19: preliminary guidance and practices. Vox Sang. 2021; 116(7): 798-807.

[22] Gilcher RO, Smith JW. Apheresis: Principles and technology of hemapheresis. Rossi's Principles of Transfusion Medicine. 2009.

[23] Assessment of plasmapheresis: report of the Therapeutics and Technology Assessment Subcommittee of the American Academy of Neurology. Neurology. 1996; 47: 840 -43.

[24] Joan C, Gloria C, Bienvenida A, Antonio B, Ana GC, Miguel L. Efficacy and safety of plasma exchange: an 11-year single-center experience of 2730 procedures in 317 patients. Transfusion and Apheresis Science. 2014; (51): 209-214.

[25] Pene F, Vigneau C, Auburtin M, Moreau D, Zahar JR, Coste J, et al. Outcome of severe adult thrombotic microangiopathies in the intensive care unit. Intensive Care Medicine. 2005; 31(1): 71-78.

[26] Darmon M, Azoulay E, Thiery G, Ciroldi M, Galicier L, Parquet N, et al. Time course of organ dysfunction in thrombotic microangiopathy patients receiving either plasma perfusion or plasma exchange. Critical Care Medicine. 2006; 34(8): 2127-33.

[27] Carrillo IG, Demelo-Rodriguez P, Ferrero ML, Anaya F. Double filtration plasmapheresis in the treatment of pancreatitis due to severe Hypertriglyceridemia. Journal of Clinical Lipidology. 2015; 9(5): 698702 .

[28] Kyriakidis AV, Raitsiou B, Sakagianni A, Harisopoulou V, Pyrgioti M, Panagopoulou A, et al. Management of acute severe hyperlipidemic pancreatitis. Digestion. 2006; 73(4): 259-64.

[29] Syed H, Bilusic M, Rhondla C, Tavaria A. Plasmapheresis in the treatment of hypertriglyceridemia-induced pancreatitis: A community hospital's experience. J Clin Apher. 2010; 25(4): 229-34.

[30] Chang CT, Tsai TY, Liao HY, Chang CM, Jheng JS, Huang WH, et al. Double filtration plasma apheresis shortens hospital admission duration of patients with severe hypertriglyceridemia-associated acute pancreatitis. Pancreas. 2016; 45(4): 606-12.

[31] Aguirre-Valencia D, Naranjo-Escobar J, Posso-Osorio I, Macía-Mejía MC, Nieto-Aristizábal I, Barrera T, et al. Therapeutic Plasma Exchange as Management of Complicated Systemic Lupus Erythematosus and Other Autoimmune Diseases. Autoimmune Dis. 2019; 2019: 5350960.

[32] Pons-Estel GJ, Salerni GE, Serrano RM, Gomez-Puerta JA, Plasin MA, Aldasoro E, et al. Therapeutic plasma exchange for the management of refractory systemic autoimmune diseases: report of 31 cases and review of the literature. Autoimmunity Reviews. 2011; 10(11): 679-84.

[33] Kim M, Martin ST, Townsend KR, Gabardi S. Antibody-mediated rejection in kidney transplantation: a review of pathophysiology, diagnosis, and treatment options. Pharmacotherapy: The Journal of Human Pharmacology and Drug Therapy. 2014; 34(7): 733-44.

[34] Gubensek J, Buturovic-Ponikvar J, Kandus A, Arnol M, Kovac J, Marn-Pernat A, et al. Plasma exchange and intravenous immunoglobulin in the treatment of antibody-mediated rejection after kidney transplantation: a single-center historic cohort study. Transplant Proc. 2013; 45(4): 1524-7.

[35] Gubensek J, Buturovic-Ponikvar J, Kandus A, Arnol M, Lindic J, Kovac D, et al. Treatment of Antibody-Mediated Rejection After Kidney Transplantation-10 Years' Experience With Apheresis at a Single Center. Therapeutic Apheresis and Dialysis. 2016; 20(3): 2405 .

[36] Brown CM, Abraham KA, O'Kelly P, Conlon PJ, Walshe JJ. Long-term experience of plasmapheresis in antibody-mediated rejection in renal transplantation. Transplant Proc. 2009; 41(9): 3690-2.

[37] Cravedi P, Kopp JB, Remuzzi G. Recent progress in the pathophysiology and treatment of FSGS recurrence. American Journal of Transplantation. 2013; 13(2): 266-74.

[38] Ponticelli C, Glassock RJ. Posttransplant recurrence of primary glomerulonephritis. Clinical Journal of the American Society of Nephrology. 2010; 5(12): 2363-72.

[39] Kashgary A, Sontrop JM, Li L, Al-Jaishi AA, Habibullah ZN, Alsolaimani $\mathrm{R}$, et al. The role of plasma exchange in treating posttransplant focal segmental glomerulosclerosis: A systematic review and meta-analysis of 77 case-reports and case-series. BMC Nephrol. 2016; 17(1): 104

[40] McLeod BC. Therapeutic apheresis: use of human serum albumin, fresh frozen plasma and cryosupernatant plasma in therapeutic plasma exchange. Best Pract Res Clin Haematol. 2006; 19(1): 157-67.
[41] Shemin D, Briggs D, Greenan M. Complications of therapeutic plasma exchange: a prospective study of 1,727 procedures. J Clin Apher. 2007; 22(5): 270-6. 